\title{
Recent Developments in Magnesium Alloy Corrosion Research
}

\author{
Nick Birbilis, R. L. Liu, Y. Yan, and O. Gharbi
}

\begin{abstract}
When exposed to atmospheric or aqueous conditions, magnesium $(\mathrm{Mg})$ undergoes corrosion, and so do $\mathrm{Mg}$ alloys. In recent years, there has been a transition from accepting the corrosion of magnesium alloys, to proactive research aimed at (1) clarifying magnesium corrosion mechanisms to devise methods for restricting magnesium corrosion, and (2) demonstration of methodologies to produce more corrosion resistant magnesium alloys.

Herein, a number of examples will be shown, selected on the basis that they represent a design directed approach. Two key systems will be highlighted, including the $\mathrm{Mg}-X$ systems, where $X$ represents group 14 and group 15 elements. It was recently demonstrated that arsenic (As) has the ability to stifle the cathodic reaction kinetics (via cathodic poisoning mechanism) upon Mg. Given the toxicity of As, alternatives with similar chemical
\end{abstract}

properties are explored, with particular focus given to germanium (Ge) additions. The addition of Ge was shown to decrease corrosion rates significantly, by a range of short and long-term tests, which also resulting in a concomitant lower rate of hydrogen evolution.

In contrast, the $\mathrm{Mg}-\mathrm{Li}$ alloy system is also explored as a corrosion resistant Mg-alloy. A critical concentration of $\mathrm{Li}$ additions to $\mathrm{Mg}(>10.5 \mathrm{wt} \% \mathrm{Li})$ have been demonstrated to allow the dynamic development of a corrosion resistant surface film consisting of lithium carbonate. Such a lithium carbonate film is stable in aqueous electrolytes, and insoluble, providing a basis for significant reduction in the dissolution (and corrosion) of $\mathrm{Mg}$.

The above alloying additions as functional additions for promoting appreciable corrosion resistance to $\mathrm{Mg}$-alloys is elaborated in the context of future Mg alloys.

N. Birbilis $(\bowtie) \cdot$ R. L. Liu · Y. Yan · O. Gharbi

Department of Materials Science and Engineering, Monash

University, Clayton, VIC, Australia

e-mail: nick.birbilis@monash.edu 